\section{(6) OPEN ACCESS}

\title{
Effects of a free school breakfast programme on children's attendance, academic achievement and short-term hunger: results from a stepped-wedge, cluster randomised controlled trial
}

\author{
Cliona Ni Mhurchu, ${ }^{1}$ Delvina Gorton, ${ }^{1}$ Maria Turley, ${ }^{1}$ Yannan Jiang, ${ }^{1}$ Jo Michie, \\ Ralph Maddison, ${ }^{1}$ John Hattie ${ }^{2}$
}

${ }^{1}$ Clinical Trials Research Unit, School of Population Health, University of Auckland, Auckland, New Zealand ${ }^{2}$ Teaching Learning and Development, Faculty of Education, University of Auckland, Auckland, New Zealand

\section{Correspondence to} Associate Professor Cliona Ni Mhurchu, Clinical Trials Research Unit, School of Population Health, University of Auckland, Private Bag 92019 ,

Auckland Mail Centre, Auckland 1142, New Zealand;

c.nimhurchu@nihi.auckland.ac.nz

Accepted 11 August 2012 Published Online First 6 October 2012

\section{ABSTRACT}

Background Free school breakfast programmes (SBPs) exist in a number of high-income countries, but their effects on educational outcomes have rarely been evaluated in randomised controlled trials.

Methods A 1-year stepped-wedge, cluster randomised controlled trial was undertaken in 14 New Zealand schools in low socioeconomic resource areas. Participants were 424 children, mean age $9 \pm 2$ years, $53 \%$ female. The intervention was a free daily SBP. The primary outcome was children's school attendance. Secondary outcomes were academic achievement, selfreported grades, sense of belonging at school, behaviour, short-term hunger, breakfast habits and food security. Results There was no statistically significant effect of the breakfast programme on children's school attendance. The odds of children achieving an attendance rate $<95 \%$ was $0.76(95 \% \mathrm{Cl} 0.56$ to 1.02$)$ during the intervention phase and $0.93(95 \% \mathrm{Cl} 0.67$ to 1.31) during the control phase, giving an $\mathrm{OR}$ of 0.81 (95\% Cl 0.59 to 1.11$), p=0.19$. There was a significant decrease in children's self-reported short-term hunger during the intervention phase compared with the control phase, demonstrated by an increase of 8.6 units on the Freddy satiety scale $(95 \% \mathrm{Cl} 3.4$ to $13.7, p=0.001)$. There were no effects of the intervention on any other outcome.

Conclusions A free SBP did not have a significant effect on children's school attendance or academic achievement but had significant positive effects on children's short-term satiety ratings. More frequent programme attendance may be required to influence school attendance and academic achievement.

Trial registration Australian New Zealand Clinical Trials Registry (ANZCTR) —ACTRN12609000854235.

\section{INTRODUCTION}

Good nutrition, particularly in the early years of life, is fundamental to health and an important component of comprehensive action to achieve health equity. ${ }^{1}$ While much resource in highincome countries is directed towards tackling obesity and other diet-related non-communicable diseases, there remains a substantial number of people in such countries who do not have sufficient nutritious food to eat and are classified as food insecure. $^{2}$

Food insecurity is an issue for $20 \%-22 \%$ of New Zealand households with children, with higher rates among Pacific peoples and Māori (indigenous New Zealanders). ${ }^{3}$ In 2002, over half of Pacific and more than one-third of Māori households with children could not always afford to eat properly. ${ }^{3}$ Living in a food insecure household impacts adversely on children's nutrition ${ }^{4}$ and has repercussions for growth, development and long-term health. Food insecure children are more likely to miss meals, ${ }^{5}$ and $17 \%$ of New Zealand children do not eat breakfast at home before school. ${ }^{3}$

School feeding programmes are intended to alleviate short-term hunger, improve nutrition and educational attainment of children and transfer income to families. ${ }^{6}$ There is evidence that such feeding programmes have positive effects on children's nutrition, health and school attendance for disadvantaged children ${ }^{7}$ and those in developing countries. ${ }^{6}$ However, the evidence is less conclusive regarding their impact on academic achievement, particularly in high-income countries.

The primary aim of this stepped-wedge, cluster randomised controlled trial was to investigate the effects of a free school breakfast programme (SBP) in New Zealand on children's school attendance. Secondary aims were examination of the impact of the breakfast programme on children's academic achievement, self-reported grades, sense of belonging at school, behaviour, short-term hunger, breakfast habits and food security.

\section{METHODS}

The study protocol and methods have been described in detail previously. ${ }^{8}$ A summary is provided below.

\section{Setting}

All New Zealand schools are assigned a decile rating, which indicates the extent to which they draw their students from a range of socioeconomic areas. Decile 1 schools are the $10 \%$ of schools with the highest proportion of students from low socioeconomic resource areas, and decile 10 schools are those with the highest proportion of students from high socioeconomic areas. There are no national government-funded school meal programmes, and while most primary schools provide some form of food service for purchase, only approximately $15 \%$ have purpose-built canteen facilities. ${ }^{9}$ Our study was undertaken in deciles 1-4 primary schools (students aged 5-13 years) located in three geographical regions (Auckland, Waikato and Wellington) during 
the 2010 school year (February to December). Ethical approval for the trial was received from the Northern Y Regional Ethics Committee (Reference: NTY/09/09/084). Written informed assent was obtained from all participating children as well as parental consent. Only children who provided both assent and parental consent were eligible to take part.

\section{Study design}

The study was a 1-year stepped-wedge, cluster randomised controlled trial ${ }^{10} 11$ in which participating schools (clusters) crossed over from control to intervention phase (ie, one-way switch over) in different terms through the school year. The order of switch over ('sequence') for each cluster was determined randomly, and all received the breakfast programme intervention by the end of study (figure 1). Each school entered the trial at the same time point (February 2010) and acted as a control until such time as they were randomised to crossover from control to intervention. ${ }^{8}$

\section{Participants and recruitment}

Eligible schools were deciles 1-4 primary schools, which did not have an existing breakfast programme and agreed to start one in the 2010 school year. Schools needed to be of sufficient size that they estimated at least 25 students would attend a breakfast programme each day. Eligible participants were children aged 5-13 years who planned to attend the SBP and did not have a diagnosed food allergy. Only one child per household could take part. Non-participation in the study did not preclude attendance at the breakfast programme.

\section{Randomisation and blinding}

Eligible schools were randomly assigned to one of the four sequences (3-4 schools per sequence) for time of crossover from control to intervention using a computer-generated list of random numbers. The allocation sequence was overseen by the study statistician (YJ). Due to the nature of the intervention, it was not possible to blind participants, breakfast providers or outcome assessors. However, the primary study outcome was objectively measured (school attendance data provided by schools).

\section{Intervention}

The intervention was a free daily SBP, either the Red Cross Breakfast in Schools programme or one provided by the private
Figure 1 Stepped-wedge, cluster randomised trial design.

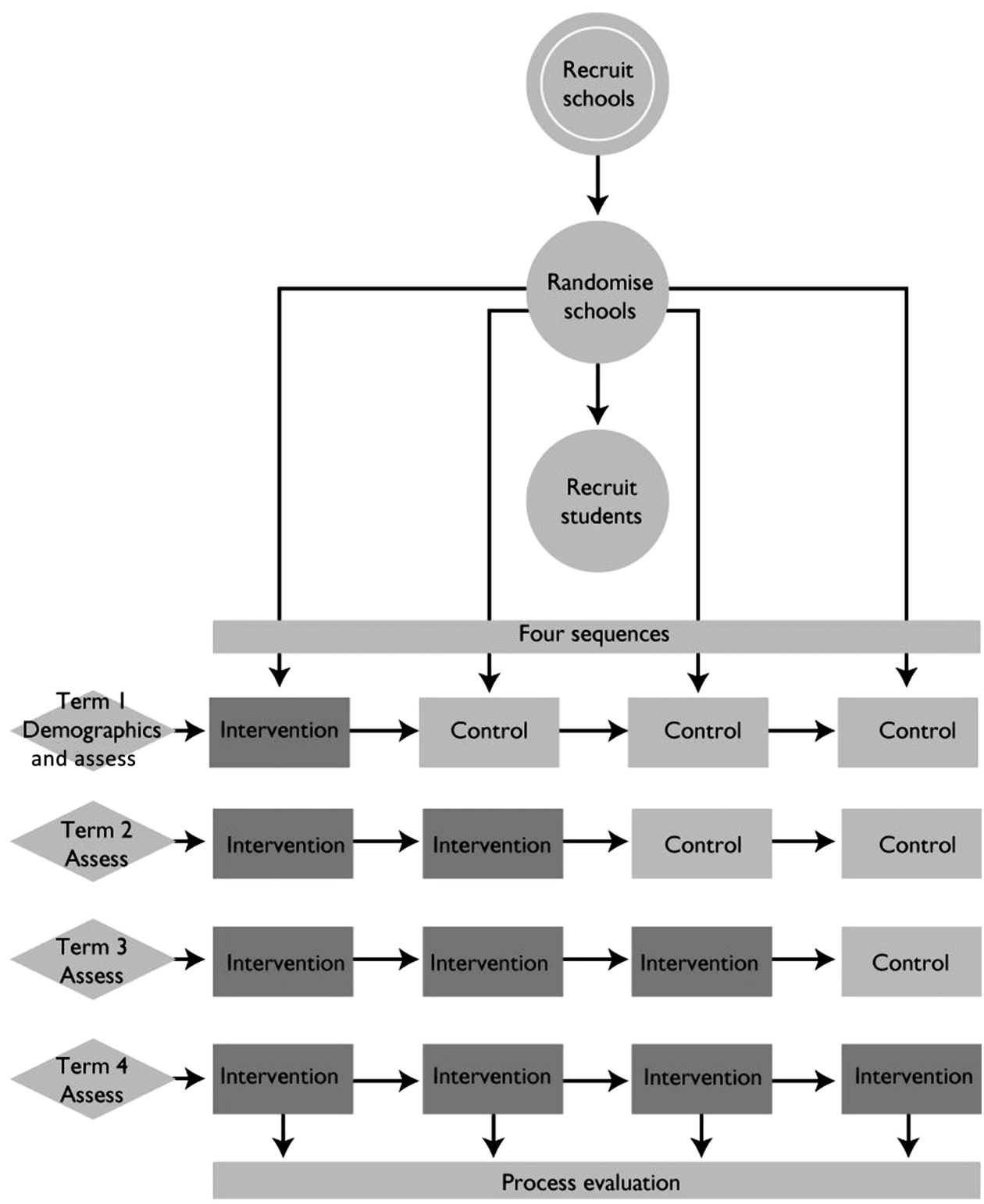


sector. In New Zealand, there are no national standards relating to the composition of foods provided by such programmes, which is reflected in the diversity of foods provided. Food for the Red Cross breakfast programme was provided free of charge by local supermarkets. Schools selected from a list of foods that included breakfast cereal (Weet-Bix), low-fat milk, bread, spreads (margarine, jam, honey, Marmite), Milo (chocolate flavoured drink powder), milk powder and sugar. Food for the private sector breakfast programme was provided by food industry partners and consisted of low-fat milk and breakfast cereal (Weet-Bix). In accordance with pragmatic trial design, no attempts were made to standardise the intervention or its delivery in schools, other than requesting that the programme be available 5 days/week.

\section{Outcomes and data collection}

The primary outcome was children's school attendance defined as achievement of a school attendance rate of $95 \%$ or higher, which equated to students missing fewer than 2-3 days per term. School attendance rate (\%) was calculated as the total number of half-days a student was present at school divided by the total number of half-days the student was expected to be present. Attendance data were recorded by schools in the usual way and provided to the study team at the end of each term.

Secondary outcomes were academic achievement assessed using numeracy and literacy data collected by schools using standardised tests administered to all New Zealand students twice yearly; children's perceived academic competence measured by asking students to make a realistic assessment of their reading ability in comparison to other students in their year at school with five responses ranging from 1 (not very well) to 5 (very well) ${ }^{12}$; self-reported sense of belonging measured using the PISA 2000 Student Engagement Questionnaire, which assesses whether students feel comfortable and as if they belong at school, and their relationship with other students ${ }^{13}$; students' behaviour, emotions and relationships assessed by teachers using the Strengths and Difficulties Questionnaire ${ }^{14}{ }^{15}$; self-reported short-term hunger assessed using a modified version of 'Freddy', an analogue scale ${ }^{1-15}$ for measuring satiety in children ${ }^{16}$; breakfast habits over the past week reported by parents (how often their children ate breakfast, where they ate breakfast and where they sourced food for breakfast $)^{3} 1^{17}$ and food security status using the CCHIP Scale, which assesses both household and child food security. ${ }^{18} 19$ All assessments were administered once each term at or around the scheduled study assessment visit (towards the end of each term) other than numeracy and literacy (standard assessments undertaken by the schools in term 2 and term 4) and attendance data (collected continuously by schools).

\section{Sample size and statistical analysis}

The target sample size was 16 schools (four per sequence) and an average of 25 students per school, that is, 400 participants. Assuming an intra-cluster correlation coefficient of 0.05 , this would provide at least $85 \%$ power, with a two-sided significance level of $\alpha=0.05$, to detect a $10 \%$ absolute change in the proportion of students with a school attendance rate of $95 \%$ or higher. Power calculations were undertaken using methods recommended for stepped-wedge trials. ${ }^{11}$

Statistical analysis was based on the principle of intention to treat. A generalised linear mixed model was used for categorical outcomes, and a linear mixed model was used for continuous outcomes, adjusting for age, gender, ethnicity and school terms (ie, secular trend). Adjustment for confounding was undertaken to limit bias due to these individual-level characteristics because the unit of randomisation was at the school (cluster) level meaning only limited school-level characteristics would be balanced by randomisation. The cluster effect by school and correlation between repeated measurements on the same child over time were taken into account in the multilevel analysis. Random-effect mixed models were fitted to account for missing data based on the assumption that data were missing at random. Statistical analyses were performed using SAS V.9.2, 2009 (SAS Institute Inc.), and R V.2.12.0, 2010 (R Foundation for Statistical Computing).

\section{RESULTS}

\section{Recruitment and participant characteristics}

Fourteen of 154 (9\%) deciles 1-4 schools in the targeted geographic regions that did not already have a SBP agreed to take part in the trial and were randomly allocated to one of the four sequences. Schools in sequence 1 started the intervention in term 1 and continued until the end of study; schools in sequence 2 switched from control to intervention in term 2 , and schools in

Table 1 Baseline characteristics of participating schools and students

\begin{tabular}{|c|c|c|c|c|c|c|c|c|c|c|c|}
\hline \multirow{3}{*}{$\begin{array}{l}\text { Randomisation } \\
\text { sequence }\end{array}$} & \multicolumn{4}{|c|}{ School characteristics } & \multicolumn{7}{|c|}{ Student characteristics } \\
\hline & \multirow[b]{2}{*}{ School } & \multirow[b]{2}{*}{ School roll, $n$} & \multirow[b]{2}{*}{ Location } & \multirow[b]{2}{*}{ Decile } & \multirow[b]{2}{*}{$\mathbf{N}(\%)$} & \multicolumn{2}{|c|}{ Sex, n (\%) } & \multicolumn{3}{|c|}{ Ethnicity, n (\%) } & \multirow{2}{*}{$\begin{array}{l}\text { Age, mean } \pm \text { SD } \\
\text { Years }\end{array}$} \\
\hline & & & & & & Female & Male & Māori & Pacific & NZEO & \\
\hline \multirow[t]{4}{*}{1} & $A$ & 208 & Hamilton & 3 & $25(6)$ & $12(48)$ & $13(52)$ & $14(56)$ & $1(4)$ & $10(40)$ & $7.7 \pm 1.7$ \\
\hline & B & 200 & Auckland & 1 & $25(6)$ & $8(32)$ & $17(68)$ & $14(56)$ & $9(36)$ & $2(8)$ & $7.8 \pm 1.7$ \\
\hline & C & 425 & Auckland & 3 & $38(9)$ & $16(42)$ & $22(58)$ & $8(21)$ & $17(45)$ & $13(34)$ & $7.5 \pm 1.6$ \\
\hline & $D$ & 529 & Auckland & 4 & $58(14)$ & $43(74)$ & $15(26)$ & $6(10)$ & $44(76)$ & 8 (14) & $11.2 \pm 0.6$ \\
\hline \multirow[t]{3}{*}{2} & $E$ & 118 & Wellington & 2 & $24(6)$ & $13(54)$ & $11(46)$ & $12(50)$ & $3(13)$ & $9(38)$ & $7.7 \pm 1.5$ \\
\hline & $\mathrm{F}$ & 332 & Auckland & 3 & $35(8)$ & $22(63)$ & $13(37)$ & $8(23)$ & $15(43)$ & $12(34)$ & $11.3 \pm 0.8$ \\
\hline & $\mathrm{G}$ & 137 & Wellington & 1 & $49(12)$ & $25(51)$ & $24(49)$ & $9(18)$ & $34(69)$ & $6(12)$ & $9.4 \pm 2.1$ \\
\hline \multirow[t]{3}{*}{3} & $\mathrm{H}$ & 516 & Auckland & 3 & $17(4)$ & $10(59)$ & $7(41)$ & $9(53)$ & 3 (18) & $5(29)$ & $11.2 \pm 0.7$ \\
\hline & I & 234 & Auckland & 2 & $27(6)$ & $14(52)$ & $13(48)$ & $7(26)$ & $19(70)$ & $1(4)$ & $8.1 \pm 1.4$ \\
\hline & $\mathrm{J}$ & 173 & Wellington & 2 & $25(6)$ & $11(44)$ & $14(56)$ & $16(64)$ & $6(24)$ & $3(12)$ & $8.3 \pm 2.0$ \\
\hline \multirow[t]{4}{*}{4} & $\mathrm{~K}$ & 263 & Hamilton & 2 & $19(5)$ & $9(47)$ & $10(53)$ & $10(53)$ & $0(0)$ & $9(47)$ & $9.4 \pm 0.5$ \\
\hline & $\mathrm{L}$ & 324 & Auckland & 3 & $33(8)$ & $11(33)$ & $22(67)$ & $7(21)$ & $12(36)$ & $14(42)$ & $11.4 \pm 0.7$ \\
\hline & M & 373 & Auckland & 2 & $39(9)$ & $23(59)$ & $16(41)$ & $21(54)$ & $13(33)$ & $4(10)$ & $8.8 \pm 1.2$ \\
\hline & $\mathrm{N}$ & 420 & Auckland & 4 & $10(2)$ & $7(70)$ & $3(30)$ & $5(50)$ & $3(30)$ & $2(20)$ & $8.6 \pm 1.4$ \\
\hline Total & 14 schools & 4252 & & & $424(100)$ & $224(53)$ & $200(47)$ & $146(34)$ & $179(42)$ & $98(23)$ & $9.4 \pm 2.0$ \\
\hline
\end{tabular}

NWEO, New Zealand European or Other. 
sequences 3 and 4 switched from control to intervention in terms 3 and 4 , respectively. By the end of the school year, all schools had commenced the breakfast programme. Nine schools were in Auckland, three in Wellington and two in Waikato, with a reasonable spread across deciles (table 1). The two decile 1 study schools received the Red Cross Breakfast in Schools programme, and the remainder received the breakfast programme provided by the private sector.

A total of 4252 students were enrolled in the 14 schools of whom 424 (10\%) met eligibility criteria and agreed to participate in the trial, with an average of 30 students per school. Randomised participants were similar to overall school profiles in terms of age, sex and ethnicity. At baseline, participants were aged $9.4 \pm 2$ years on average, and $53 \%$ were female (table 1 ). One hundred and forty-six of the 424 participants were in schools that started the intervention in term 1, 108 started in term 2, 69 started in term 3 and 101 started in term 4 (figure 2). Fifteen students (3.5\%) withdrew from the trial and 34 (8\%) were lost to follow-up, in all cases due to their moving schools.

\section{Breakfast programme attendance}

Data on programme attendance were collected from school breakfast rolls (table 2). The number of days programmes were operational compared with total number of days schools were open ranged from $36 \%$ (school $\mathrm{F}$ in term 2 ) to $100 \%$ (school D in term 3); however, by term 4, all schools were offering the breakfast programme at least $64 \%$ of days they were open for teaching. Students' breakfast attendance was defined as average weekly attendance rate (\%) (ie, number of days students attended the programme divided by total number of days the programme was open during a week and averaged per school term). In term 4 when all breakfast programmes were operational, student attendance ranged from $4 \%$ to $38 \%$.

\section{School attendance}

Attendance rates at all schools declined gradually over the school year. In schools randomised to start the breakfast programme in term 1 (sequence 1), the proportion of children achieving

Figure 2 Flow of participants through the trial. a school attendance rate $\geq 95 \%$ ranged from $65 \%$ in term 1 to $45 \%$ in term 4 (table 3 ). For those randomised to start in term 2 (sequence 2 ), the proportion of children achieving an attendance rate $\geq 95 \%$ ranged from $65 \%$ in term 1 to $58 \%$ in term 4 . A similar pattern was seen for schools in sequences 3 and 4 .

There was no statistically significant effect of the free breakfast programme intervention on children's school attendance. The odds of children achieving an attendance rate $<95 \%$ was $0.76(95 \%$ CI 0.56 to 1.02$)$ during the intervention phase and 0.93 (95\% CI 0.67 to 1.31 ) during the control phase, giving an OR of 0.81 ( $95 \%$ CI 0.59 to 1.11 , p value 0.19 ) (table 4 ).

\section{Secondary outcomes}

There was a significant decrease in children's self-reported shortterm hunger during the intervention phase compared with the control phase, demonstrated by an increase of 8.6 units on the Freddy satiety scale (95\% CI 3.4 to $13.7, \mathrm{p}=0.001$ ). However, there were no effects of the SBP on any other secondary outcomes measured (table 5).

Over the 2010 school year, average improvements at school level in children's reading $(0.48 \pm 0.43)$, writing $(0.47 \pm 0.16)$ and numeracy $(0.56 \pm 0.39)$ were in line with expected achievements over time. ${ }^{20}$ A random-effect mixed model demonstrated no consistent significant effect of the intervention on academic outcomes (data available on request).

While the proportion of children who ate breakfast everyday did not change over the course of the trial, the proportion eating breakfast at home dropped as schools began the breakfast programme. Figure 3 demonstrates that as new schools started the breakfast programme each term, there was an increase in the proportion of children eating breakfast at school and a corresponding decrease in the proportion of children eating breakfast at home most days. This suggests that many children who previously ate breakfast at home replaced this with breakfast at school.

\section{Sensitivity analysis}

School breakfast roll data and parents' feedback on children's breakfast habits suggested that attendance at the breakfast

\section{Participant flow}

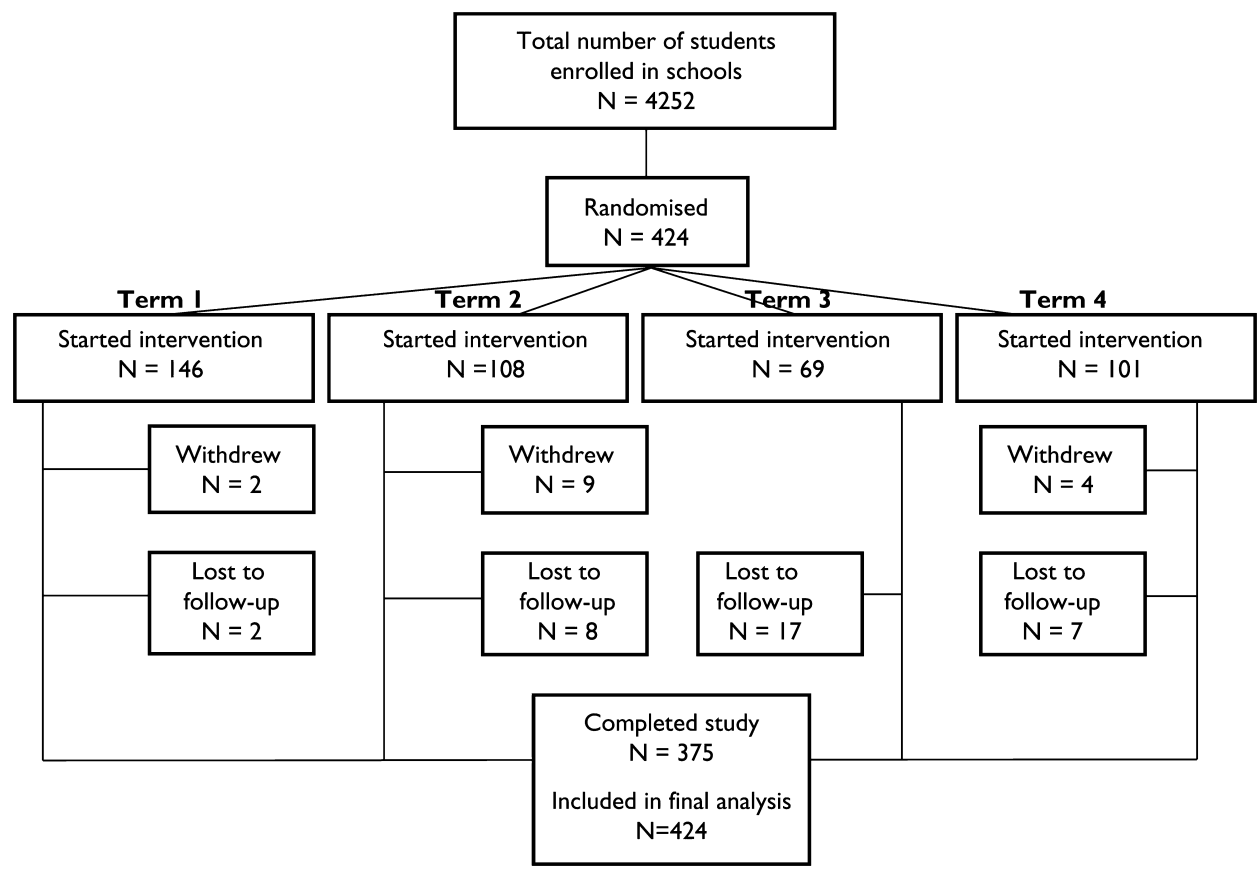


Table 2 Breakfast programme attendance throughout the tria

\begin{tabular}{|c|c|c|c|c|c|c|c|c|}
\hline \multirow[b]{2}{*}{ Schools } & \multicolumn{2}{|c|}{ Term 1 (9 weeks) } & \multicolumn{2}{|c|}{ Term 2 (11 weeks) } & \multicolumn{2}{|c|}{ Term 3 (10 weeks) } & \multicolumn{2}{|c|}{ Term 4 (9 weeks) } \\
\hline & $\begin{array}{l}\text { Days } \\
\text { programme } \\
\text { opened, n (\%) }\end{array}$ & $\begin{array}{l}\text { Students' } \\
\text { average } \% \text { weekly } \\
\text { attendance rate, } \\
\text { mean } \pm \text { SD }\end{array}$ & $\begin{array}{l}\text { Days } \\
\text { programme } \\
\text { opened, n (\%) }\end{array}$ & $\begin{array}{l}\text { Students' } \\
\text { average \% weekly } \\
\text { attendance rate, } \\
\text { mean } \pm \text { SD }\end{array}$ & $\begin{array}{l}\text { Days } \\
\text { programme } \\
\text { opened, n (\%) }\end{array}$ & $\begin{array}{l}\text { Students' } \\
\text { average \% weekly } \\
\text { attendance rate, } \\
\text { mean } \pm \text { SD }\end{array}$ & $\begin{array}{l}\text { Days } \\
\text { programme } \\
\text { opened, n (\%) }\end{array}$ & $\begin{array}{l}\text { Students' } \\
\text { average } \% \text { weekly } \\
\text { attendance rate, } \\
\text { mean } \pm \text { SD }\end{array}$ \\
\hline A & $33(73)$ & $33 \pm 27$ & 49 (89) & $30 \pm 29$ & 37 (78) & $25 \pm 28$ & $44(98)$ & $23 \pm 28$ \\
\hline$B$ & $34(76)$ & $54 \pm 37$ & $50(91)$ & $50 \pm 39$ & $48(96)$ & $46 \pm 34$ & $36(80)$ & $34 \pm 31$ \\
\hline C & $29(64)$ & $27 \pm 31$ & $54(98)$ & $32 \pm 33$ & $25(50)$ & $27 \pm 29$ & $44(98)$ & $14 \pm 15$ \\
\hline$D$ & $25(56)$ & $36 \pm 29$ & $50(91)$ & $64 \pm 19$ & $50(100)$ & $79 \pm 13$ & $43(96)$ & $14 \pm 20$ \\
\hline$E$ & & & 48 (87) & $56 \pm 23$ & 41 (82) & $32 \pm 30$ & 42 (93) & $38 \pm 33$ \\
\hline $\mathrm{F}$ & & & $20(36)$ & $9 \pm 19$ & $38(76)$ & $5 \pm 19$ & $32(71)$ & $5 \pm 15$ \\
\hline G & & & $29(53)$ & $49 \pm 28$ & $49(98)$ & $33 \pm 30$ & 44 (98) & $23 \pm 24$ \\
\hline $\mathrm{H}$ & & & & & $26(52)$ & $20 \pm 29$ & $29(64)$ & $4 \pm 13$ \\
\hline I & & & & & - & - & - & - \\
\hline J & & & & & $45(90)$ & $22 \pm 33$ & 44 (98) & $21 \pm 31$ \\
\hline K & & & & & & & - & - \\
\hline $\mathrm{L}$ & & & & & & & $34(76)$ & $34 \pm 32$ \\
\hline M & & & & & & & - & - \\
\hline $\mathrm{N}$ & & & & & & & - & - \\
\hline
\end{tabular}

-, Breakfast programme attendance data were not available for school (all such values).

programme was irregular, and it is possible that the effect of the breakfast programme on study outcomes was diluted by low attendance at the programme. Therefore, we conducted sensitivity analyses of the effects of the free SBP on the primary study outcome, school attendance, in a subgroup of the population who attended the programme more frequently, that is, $50 \%$ or more of the time. The odds of these children achieving a school attendance rate $<95 \%$ was $0.58(95 \%$ CI 0.40 to 0.83$)$ during the intervention phase and 0.89 (95\% CI 0.60 to 1.33$)$ during the control phase, giving an OR of 0.64 (95\% CI 0.42 to 0.99 , p value 0.047). School attendance rate (a continuous outcome) was on average 93.9\% (SE 0.57) for the intervention phase and $92.3 \%$ (SE 0.61) for the control phase, with a difference of $1.6 \%$ points (SE 0.65), which was statistically significant ( $p$ value 0.016 ).

\section{DISCUSSION}

In this stepped-wedge, cluster randomised controlled trial, a free SBP did not have a significant effect on children's school attendance, academic achievement, self-reported grades, sense of belonging at school, behaviour or food security. However, the programme had significant positive effects on children's shortterm hunger ratings. Although most schools offered the breakfast programme 5 days per week, recorded weekly student attendance ranged from $4 \%$ to $38 \%$ of days. Sensitivity analyses conducted with children who attended the programme more frequently (at least $50 \%$ of the time it was available) demon- strated a significant effect of the breakfast programme on school attendance among this subgroup.

The strengths of this trial include its large sample size, high follow-up rates (88\% of randomised children), use of objective measures of school attendance and academic achievement, and pragmatic design, which allowed evaluation of the effects of a breakfast programme as implemented in routine practice. ${ }^{21}$ The population was diverse, drawn from low socioeconomic resource areas and included substantially higher proportions of Māori (34\%) and Pacific (42\%) children than would be expected on the basis of their representation in the population $(24 \%$ and $12 \%$, respectively). ${ }^{22}$

Study limitations include potential selection bias, whereby the children who entered the trial may have been different in important ways from average deciles 1-4 school populations. While our study population was not substantially different from overall school rolls in terms of age, gender and ethnicity, they may have differed in other unmeasured socio-demographic factors, for example, household income or parental education level. It is possible that the programme could produce more positive effects among children at greater need of a school feeding programme not enrolled in the trial.

Variable breakfast composition (cereal and milk in some schools and cereal, bread, milk and chocolate flavoured drinks in others) and reduced availability of the breakfast programme in some schools (fewer than 5 days/week) may also have limited

Table 3 School attendance rates throughout the trial

\begin{tabular}{|c|c|c|c|c|c|}
\hline & & Term $1(n=136)$ & Term $2(n=138)$ & Term $3(n=132)$ & Term $4(n=128)$ \\
\hline \multirow[t]{3}{*}{ Sequence 1} & Attendance rate (\%) & $94.5 \pm 7.4$ & $92.7 \pm 8.0$ & $91.1 \pm 9.5$ & $90.2 \pm 12.4$ \\
\hline & Attendance rate $\geq 95 \%$ & $89(65.4 \%)$ & $75(54.3 \%)$ & $57(43.2 \%)$ & $57(44.5 \%)$ \\
\hline & & Term $1(n=106)$ & Term $2(n=103)$ & Term $3(n=96)$ & Term $4(n=96)$ \\
\hline \multirow[t]{3}{*}{ Sequence 2} & Attendance rate (\%) & $95.1 \pm 5.8$ & $94.4 \pm 6.7$ & $91.8 \pm 10.1$ & $91.4 \pm 14.5$ \\
\hline & Attendance rate $\geq 95 \%$ & $69(65.1 \%)$ & $66(64.1 \%)$ & $47(49.0 \%)$ & $56(58.3 \%)$ \\
\hline & & Term $1(n=65)$ & Term $2(n=66)$ & Term $3(n=62)$ & Term $4(n=60)$ \\
\hline \multirow[t]{3}{*}{ Sequence 3} & Attendance rate (\%) & $93.4 \pm 7.8$ & $92.8 \pm 9.6$ & $90.1 \pm 14.5$ & $90.6 \pm 9.4$ \\
\hline & Attendance rate $\geq 95 \%$ & $40(61.5 \%)$ & $35(53.0 \%)$ & $27(43.5 \%)$ & $27(45.0 \%)$ \\
\hline & & Term $1(n=95)$ & Term $2(\mathrm{n}=78)$ & Term $3(n=59)$ & Term $4(n=58)$ \\
\hline \multirow[t]{2}{*}{ Sequence 4} & Attendance rate $(\%)$ & $95 \pm 5.5$ & $93.3 \pm 7.8$ & $91.2 \pm 8.1$ & $91.7 \pm 8.6$ \\
\hline & Attendance rate $\geq 95 \%$ & $59(62.1 \%)$ & $43(55.1 \%)$ & $25(42.4 \%)$ & $27(46.6 \%)$ \\
\hline
\end{tabular}

Values represent mean $\pm S D$ or $n(\%)$. 
Table 4 Estimates of effect of free school breakfast programme on children's school attendance

\begin{tabular}{|c|c|c|c|c|c|c|c|}
\hline \multicolumn{4}{|c|}{ Probability of school attendance rate $<95 \%$} & \multicolumn{4}{|l|}{ OR* } \\
\hline & Estimate & Lower $95 \% \mathrm{Cl}$ & Upper $95 \% \mathrm{Cl}$ & Estimate & Lower $95 \% \mathrm{Cl}$ & Upper $95 \%$ Cl & p Value \\
\hline Intervention & 0.43 & 0.36 & 0.51 & 0.81 & 0.59 & 1.11 & 0.19 \\
\hline Control & 0.48 & 0.40 & 0.57 & & & & \\
\hline
\end{tabular}

A generalised linear mixed model was used to evaluate the main treatment effect between intervention and control phases, adjusting for age, gender, ethnicity and school terms (ie, secular trend). School was fitted as a random effect to adjust for the cluster effect and the variability across schools.

*Reference group is those who achieved an attendance rate of $95 \%$ or higher; $0 \mathrm{R}<1$ indicates a better treatment effect if statistically significant.

the impact of the intervention. Data on breakfast programme attendance rates were missing for four schools in term 4 . These schools did not complete breakfast rolls because they reported that the number of registered study participants attending the programme was low (less than five registered students per day per school). However, this was a pragmatic trial and the main trial effects observed likely reflect those of a real-life breakfast programme.

Finally, the relatively low attendance rates by study participants at the breakfast programme and the likelihood that many, rather than increasing breakfast consumption, simply replaced breakfast at home with breakfast at school almost certainly influenced the absence of effect on study outcomes. In combination, these factors could explain the lack of observed effect of the breakfast programme on the range of outcomes assessed; both have previously been identified as reasons why school feeding programmes may not be effective. ${ }^{23}$ Our sensitivity analysis supports the hypothesis that breakfast programme attendance rates influenced study outcomes because there was a significant positive effect on school attendance for children who attended the programme more regularly. Low attendance at the breakfast programme most likely reflects the typical 'healthy volunteer' selection bias seen in many trials. Families who consented to participate in the study and completed questionnaires are likely to have been those least in need of a free breakfast programme.

In the UK, government-funded school feeding programmes date back to the early 20 th century. ${ }^{24}$ Recently, an interesting natural experiment took place when British chef, Jamie Oliver, undertook a campaign to improve nutritional standards in schools. Evaluation of the campaign found that educational outcomes improved significantly in intervention schools and school absences fell by $14 \% .^{25}$ Although the evaluation was conducted with careful matching of control schools, it was not a prospective randomised controlled trial and, as such,

Table 5 Estimated effect of free school breakfast programme on children's educational and other outcomes

\begin{tabular}{lcccl}
\hline & $\begin{array}{l}\text { Effect* } \\
\text { (intervention vs } \\
\text { control phase) }\end{array}$ & $\begin{array}{l}\text { Lower } \\
\text { 95\% Cl }\end{array}$ & $\begin{array}{l}\text { Upper } \\
\mathbf{9 5 \%} \text { Cl }\end{array}$ & p Value \\
\hline School attendance rate (0\%-100\%) & 0.25 & -0.82 & 1.32 & 0.65 \\
Self-reported reading grades (1-5) & 0.06 & -0.07 & 0.19 & 0.38 \\
Sense of belonging (1-4) & -0.02 & -0.08 & 0.04 & 0.53 \\
Total SDO score (0-40) & -0.10 & -0.69 & 0.48 & 0.73 \\
Short-term satiety (0-150) & 8.56 & 3.42 & 13.69 & 0.001 \\
Food security (study child) & 0.92 & 0.70 & 1.22 & 0.55 \\
Food security & 0.89 & 0.67 & 1.18 & 0.43 \\
(all children in household) & & & &
\end{tabular}

${ }^{*}$ A linear mixed model was used on continuous outcomes to estimate the treatment difference in means, adjusting for age, gender, ethnicity and school terms (ie, secular trend). School was fitted as a random effect to adjust for the cluster effect and the variability across schools. A generalised linear mixed model was used on binary outcomes to estimate the $\mathrm{OR}$ and its $95 \% \mathrm{Cl}$.

SDQ, Strengths and Difficulties Questionnaire. confounding cannot be ruled out. An alternative explanation, however, may relate to frequency of consumption of school meals. About $45 \%$ of British schoolchildren eat school dinners every day, ${ }^{25}$ whereas children in our trial, only attended the breakfast programme $4 \%-38 \%$ of the time it was open. Thus, it is possible that frequent regular consumption of healthy school meals is necessary to impact on attendance and academic achievement.

\section{Breakfast everyday}
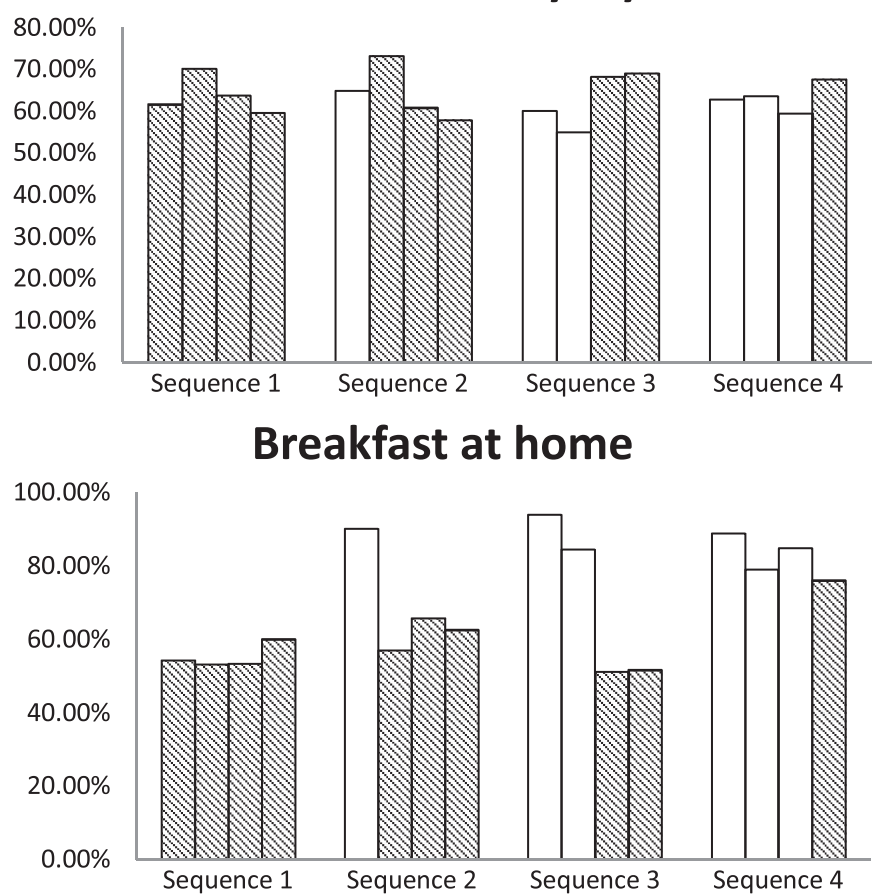

Breakfast at school

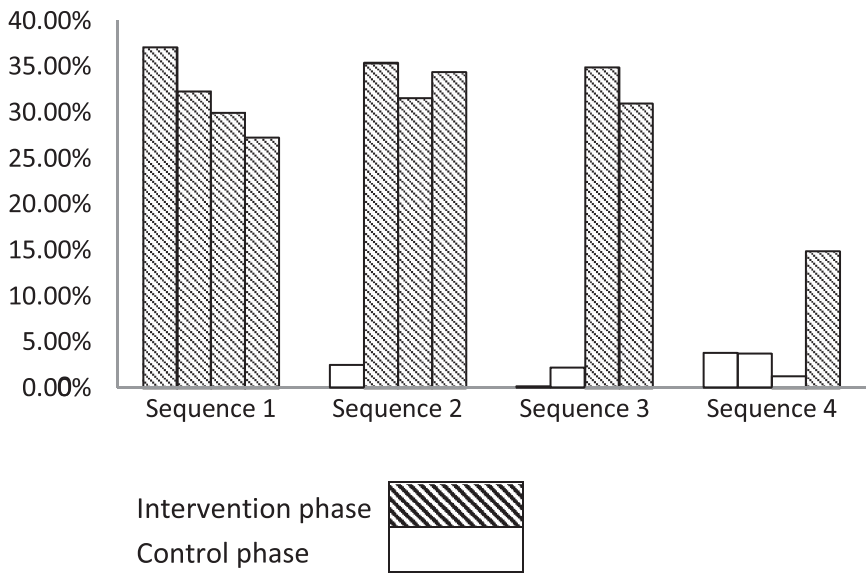

Figure 3 Reported breakfast habits over the course of the 10-month trial. 


\section{What is already known on this subject}

School feeding programmes are intended to alleviate short-term hunger, improve nutrition and educational attainment of children, and transfer income to families. There is evidence that such programmes have positive effects on children's nutrition, health and school attendance for disadvantaged children and those in developing countries. However, the evidence is less conclusive regarding impact on academic achievement, particularly in high-income countries.

\section{What this study adds}

A free SBP did not have a significant effect on New Zealand children's school attendance, academic achievement, selfreported grades, sense of belonging at school, behaviour or food security. However, the programme had significant positive effects on children's short-term hunger ratings. More frequent programme attendance may be required to influence school attendance and academic achievement.

In 2004, a large, cluster randomised controlled trial was undertaken of a Welsh government-funded free breakfast programme for primary schools. ${ }^{26}$ Primary outcomes were breakfast skipping, episodic memory and breakfast diet. ${ }^{27}$ Attendance at the Welsh breakfast programme was relatively low, and there was no evidence of an effect on breakfast skipping, episodic memory or class behaviour, although students reported consuming significantly higher numbers of healthy food items at breakfast. ${ }^{27}$ Similar to our trial, there was a move from home to school-based breakfast eating among children.

The US Department of Agriculture subsidises the SBP. ${ }^{28}$ While a number of evaluations indicate that the SBP contributes to improved nutrition among programme participants, ${ }^{29}{ }^{30} \mathrm{few}$ have examined effects on aspects of school performance. A small study ( $n=133$ children) suggested higher rates of participation in the SBP were associated with improved psychosocial and academic functioning. ${ }^{31}$ However, there was no comparative control group. Another non-randomised study found evidence of improved academic performance in children participating in the SBP but was also small ( $n=97$ students) and findings were based on subgroup analysis. ${ }^{18}$

Thus, most research on the impact of SBPs on children's health and educational outcomes in high-income countries has taken the form of evaluations and cannot exclude the effects of confounding. Robust randomised controlled trials have not found an effect of SBPs on school attendance, academic achievement, memory or behaviour. ${ }^{27}$ However, relatively low breakfast programme attendance and moves from home to school-based breakfast consumption may account for lack of observed effects.

This research demonstrated that a non-standardised free SBP in New Zealand alleviated children's short-term hunger but did not impact on children's school attendance, academic achievement or behaviour. More frequent programme attendance may be required to influence school attendance and academic achievement.

Acknowledgements We thank the schools, children and families who took part in the study and the providers of the breakfast programmes: the New Zealand Red
Cross, Progressive Enterprises (Countdown supermarkets), Fonterra Co-operative Group Limited and Sanitarium Health Food Company. We are grateful for the input and assistance of our steering committee members (Sara Williams, Kate Kember, Tia Wylie, Christine McKerchar, Leonie Matoe), research assistants (Denise Miller, Oliver Allen), data manager (Vanessa Singh), data analyst (Joy Jiang) and CTRU IT and operations staff.

Contributors Principal responsibility for study design was assumed by DG, YJ, RM and CNM. DG, JM and MT developed the study protocol and materials. DG was the principal investigator from July to October 2009. MT was the principal investigator from November 2009 to August 2010. JH had substantial input into study design and oversight. JM was responsible for day-to-day study management. YJ was responsible for all aspects of statistical design and analysis. CNM was the principal investigator from August 2009 onwards and drafted the study manuscript integrating contributions from all coauthors. All authors approved the final manuscript. CNM had full access to all data in the study and takes responsibility for integrity of the data and the accuracy of the data analysis.

Funding The study was funded by the Health Research Council of New Zealand (09/337). CNM holds the National Heart Foundation Senior Fellowship (grant 1380). The Health Research Council and the Heart Foundation played no role in design and conduct of the study; collection, management, analysis and interpretation of the data; or preparation, review or approval of the manuscript. Food for the Red Cross Breakfast in Schools programme was provided free of charge by Countdown supermarkets (Progressive Enterprises Ltd). Fonterra Co-operative Group Limited and Sanitarium Health Food Company supplemented provision of foods for the private sector programme. The Red Cross, Countdown, Fonterra and Sanitarium played no role in design and conduct of the study; collection, management, analysis and interpretation of the data; and preparation or approval of the manuscript.

\section{Competing interests None.}

Patient consent Both child assent and parental consent were obtained for each participant.

Ethics approval The ethics approval was provided by the Northern $Y$ Regional Ethics Committee (Reference: NTY/09/09/084).

Provenance and peer review Not commissioned; externally peer reviewed.

Data sharing statement Any additional unpublished data can be made available to academic researchers on request.

Open Access This is an Open Access article distributed in accordance with the Creative Commons Attribution Non Commercial (CC BY-NC 3.0) license, which permits others to distribute, remix, adapt, build upon this work non-commercially, and license their derivative works on different terms, provided the original work is properly cited and the use is non-commercial. See: http://creativecommons.org/licenses/by-nc/3.0/

\section{REFERENCES}

1. Marmot M, Friel S, Bell R, et al. Closing the gap in a generation: health equity through action on the social determinants of health. Lancet 2008:372:1661-9.

2. Cook JT, Frank DA, Berkowitz C, et al. Food insecurity is associated with adverse health outcomes among human infants and toddlers. $J$ Nutr 2004;134:1432-8.

3. Ministry of Health. NZ Food NZ Children: Key Results of the 2002 National Children's Nutrition Survey. Wellington: Ministry of Health, 2003.

4. Pilgrim A, Barker M, Jackson A, et al. Does living in a food insecure household impact on the diets and body composition of young children? Findings from the Southampton Women's Survey. J Epidemiol Community Health 2012;66:6 e6.

5. Utter J, Denny S, Robinson E, et al. Food security concerns among young people: impact on eating behaviors and weight status. $J$ Hunger Environ Nutr 2011:7:101-11.

6. Jomaa LH, McDonnell E, Probart C. School feeding programs in developing countries: impacts on children's health and educational outcomes. Nutr Rev 2011;69:83-98.

7. Kristjansson B, Petticrew M, MacDonald B, et al. School feeding for improving the physical and psychosocial health of disadvantaged students (Review). Cochrane Database Syst Rev 2007;(1):CD004676. doi:10.1002/14651858.CD004676.pub2

8. Ni Mhurchu C, Turley M, Gorton D, et al. Effects of a free school breakfast programme on school attendance, achievement, psychosocial function, and nutrition: a stepped wedge cluster randomised trial [Study protocol]. BMC Public Health 2010;10:738.

9. Carter MA, Swinburn B. Measuring the 'obesogenic' food environment in New Zealand primary schools. Health Promot Int 2004;19:15-20.

10. Brown CA, Lilford RJ. The stepped wedge trial design: a systematic review. BMC Med Res Methodol 2006:6:54.

11. Hussey MA, Hughes JP. Design and analysis of stepped wedge cluster randomized trials. Contemp Clin Trials 2007;28:182-91.

12. Mabe PA, West SG. Validity of self-evaluation of ability: a review and meta-analysis J App/ Psy 1982;67:280-96 
13. Willms J. Student Engagement at School: A Sense of Belonging and Participation Results from PISA 2000. Paris: Organisation for Economic Cooperation and Development, 2003

14. Goodman A, Goodman R. Strengths and difficulties questionnaire as a dimensional measure of child mental health. J Am Acad Child Adolesc Psychiatry 2009:48:400-3

15. Hawes DJ, Dadds MR. Australian data and psychometric properties of the strengths and difficulties questionnaire. Aust N Z J Psychiatry 2004;38:644-51.

16. Keller KL, Assur SA, Torres $\mathbf{M}$, et al. Potential of an analog scaling device for measuring fullness in children: development and preliminary testing. Appetite 2006:47:233-43.

17. Ministry of Health. A Portrait of Health: Key Results of the 2002/03 New Zealand Health Survey. Wellington: Ministry of Health, 2004.

18. Kleinman RE, Hall S, Green $\mathrm{H}$, et al. Diet, breakfast, and academic performance in children. Ann Nutr Metab 2002; 46(Suppl 1):24-30.

19. Frongillo EA Jr, Rauschenbach BS, Olson CM, et al. Questionnaire-based measures are valid for the identification of rural households with hunger and food insecurity. J Nutr 1997;127:699-705.

20. Hattie JAC. Visible Learning: A Synthesis of $800+$ Meta-analyses on Achievement. Oxford, UK: Routledge, 2009.

21. Mdege ND, Man MS, Taylor Nee Brown CA, et al. Systematic review of stepped wedge cluster randomized trials shows that design is particularly used to evaluate interventions during routine implementation. J Clin Epidemiol 2011;64:936-48.
22. Statistics New Zealand. National Population Estimates: March 2011 Quarter. Wellington: Statistics New Zealand, 2011.

23. Greenhalgh T, Kristjansson E, Robinson V. Realist review to understand the efficacy of school feeding programs. BMJ 2007;335:858-61.

24. Marrack JR. School meals and milk. Public Health 1946;59:178-80.

25. Belot M, James J. Healthy school meals and educational outcomes. J Health Econ 2011;30:489-504.

26. Moore L, Moore GF, Tapper K, et al. Free breakfast in schools: design and conduct of a cluster randomised controlled trial of the Primary School Free Breakfast Initiative in Wales [ISRCTN18336527]. BMC Public Health 2007; 7:258.

27. Murphy S, Moore G, Tapper K, et al. Free healthy breakfasts in primary schools: a cluster randomised controlled trial of a policy intervention in Wales, UK. Public Health Nutr 2010;14:219-26.

28. Kennedy E, Davis C. US department of agriculture school breakfast program. Am J Clin Nutr 1998;67:798S-803.

29. Crepinsek MK, Singh A, Bernstein LS, et al. Dietary effects of universal-free schoo breakfast: findings from the evaluation of the school breakfast program pilot project. J Am Diet Assoc 2006;106:1796-803.

30. Friedman BJ, Hurd-Crixell SL. Nutrient intake of children eating school breakfast. J Am Diet Assoc 1999:99:219-21.

31. Murphy JM, Pagano ME, Nachmani J, et al. The relationship of school breakfast to psychosocial and academic functioning: cross-sectisnal an joncitucinal cisservation in an inner-city school sample. Arch Pediatr Adolesc Med 1998;152:899-907. 